\title{
PESSOAL
}

\section{Nova Atitude em Matéria de Pessoal}

\author{
Tradução de Thomaz Newlands Neto
}

\begin{abstract}
Do livro de Public Administration, de Marshall Edward Dimock e GLADYS OGDEN DIMOcK, cuja tradução brasileira será publicada pela "Fundação Getúlio Vargas".
\end{abstract}

A TÉ alguns anos passados, notava-se fundamental diferença de pontos de vista entre a indústria e a administração pública, com respeito às atividades de pessoal. A indústria atribuia relêvo à responsabilidade dos chefes de linha, ao passo que o govêrno federal e, igualmente, o de outras órbitas administrativas que possuíam comissões de serviço civil realçavam as funções de staff e restringiam a alçada daqueles chefes. Nos últimos quinze anos, porém, a mudança de atitude em matéria de administração de pessoal, quer na indústria quer na administração, reduziu de algum modo as divergências.

$\mathrm{Na}$ indústria, a importância de acentuar-se o elemento humano na administração de pessoal teve lento desenvolvimento, embora seja hoje em dia, fator dominante. Outrora, quase todos os departamentos de pessoal das emprêsas de negócios se preocupavam, de modo geral, com problemas de seguro dos empregados, sua saúde, assentamentos pessoais e admissão, no pressuposto de que outras funções quaisquer eram de responsabilidade dos chefes de linhas.

Com o crescente poderio dos sindicatos profissionais e o aumento das tensões pessoais promanadas de situações de rotina no trabalho, bem como da instabilidade do meio social, compreendeu a indústria a necessidade de serem organizados, em bases sólidas, departamentos de pessoal e de relações no trabalho, que dessem atenção aos aspectos humanos do problema. Essa tendência representa um dós relevantes progressos da sabedoria administrativa realizados nos últimos vinte anos.

No govêrno federal, como vimos, a reforma do serviço público civil iniciou-se com a Lei Pendleton, de 1883, expandindo-se a pouco e pouco pelos governos estaduais e locais. Foram a princípio destacados, predominantemente, os aspectos negativos e de defesa, sendo propósito declarado de reforma a "luta contra o nepotismo".

Sòmente nos primórdios da década dos trinta é que se reconheceu a vantagem de um modo de vêr mais positivo nesse setor, sendo empregados funcionários de staff, especialmente preparados. 
Houve luta para encontrar-se um aceitável equilíbrio entre os dois extremos: um dêles, consistindo na garantia formal do sistema do mérito, na atribuição de um papel policial às comissões de serviço civil; o recrutamento em massa era realizado em bases predominantemente mecânicas. $O$ outro extremo era favorável a um programa positivo de recrutamento, designação, treinamento e promoções e também ao emprêgo sistemático de funcionários de staff e linha nas repartições executivas, insistindo nos critérios de seletividade e flexibilidade.

Ninguém situou o problema em melhores têrmos do que FLOYd REEVES, criador do departamento de pessoal da Autoridade do Vale do Tennessee, e. posteriormente, autor de monografia sôbre pessoal, escrita para a Comissão Presidencial de Administração, (Brownlow Committee). Em candente mas construtivo artigo sob o título "Continua na mesma o Serviço Público" (Civil Service as Usual), descreve Reeves os critérios negativos que afeiçoaram os primeiros cinqüenta anos da administração de pessoal, na órbita federal. Uma repartição central, a Comissão do Serviço Civil (Civil Service Comission) veio a dispor de grande soma de poderes e autoridade; e embora a necessidade de tal órgão não seja por êle posta em dúvida, os seus méritos e processos e, de modo especial as suas atitudes, são devidamente expostas a minudente análise. Essa Comissão, prossegue REEves, dá excessivo aprêço a inflexíveis e antiquadas fichas de arquivo (relações de pessoas aprovadas em concursos), de que se vale para preencher cargos geralmente análogos embora, na realidade, diferentes no que concerne a funções específicas. Em conseqüência disso, as repartições executivas têm-se visto a braços com a impossibilidade de conseguir o pessoal habilitado de que necessitam, e os postos acabam por ser preenchidos por pessoas que não são aptas para os mesmos. O sistema do mérito, administrado sem imaginação, é suscetível de produzir uma rígida uniformidade, dotada de pouco ou nenhum mérito. O critério mecanicista, em essência um mero processo negativo, visa primordialmente a impedir o favoritismo e a influência da política nas nomeações para o serviço público federal. Só agora o sistema do mérito se converte em atitude positiva, de que o elemento humano é o aspecto central.

Foi o prevalecer de processos e regulamentos antiquados que determinou a derrocada virtual do sistema do mérito no serviço público civil federal, ocorrida em muitos lugares, durante a Segunda Guerra Mundial. Desde o fim da luta, porém, têm sido envidados esforços no sentido de corrigir alguns dos piores vícios encontrados, de tal modo que não são tão procedentes as críticas de Reeves, como o foram há dez anos. Não obstante, o presidente da Comissão do Serviço Civil, no relatório apresentado em 1952 ao Congresso declarou que, no ano anterior, a metade de todos os novos servidores federais admitidos haviam sido incluídos nas fôlhas de pagamento sem se submeterem a concurso, porque a Comissão não dispusera de verba e de pessoal para realizar aquelas admissões como de costume, e as tepartições interessadas tiveram de efetuar em grande parte, a sua própria seleção. E' possível que os fundos disponíveis tivessem bastado, se os processos de recrutamento e as provas dos concursos houvessem sido mais simples. 
A ADEQUADA DIVISÃo DE FUNÇÕES NUM SISTEMA DE PESSOAL

Já se afirmou que qualquer sistema de pessoal, quer na esfera dos negócios quer na órbita do govêrno, no campo federal ou noutro de nível inferior, há de incluir processos de recrutamente, seleção, admissão, classificação, administração, remuneração, dispensa, substituição e aposentadoria dos servidores. De que modo deverão ser essas funções divididas, na administração pública entre as repartições executivas, de um lado, e a Comissão Central de Serviço Civil, do outro, e, bem assim - no campo governamental como no mundo dos negócios - entre os chefes de linha, que exigem trabalho dos servidores, e o diretor de pessoal, que ocupa um pôsto de staff e é responsável pela administração geral do sistema de pessoal?

E' aspecto normal da vida das instituições o fato de qualquer órgão rque se encontre em posição de responsabilidade. procurar incessantemente aumentar a sua esfera de influência. Ficou demonstrado que a Comissão do Serviço Civil, de Washington, não fugiu à regra. Se essa tendência é levada além dos limites, rompe-se o devido equilíbrio de responsabilidade das repartições que se articulam numa única estrutura, como acontece na administração pública e nas grandes emprêsas, com prejuízo do moral da eficiência e da marcha dêsses órgãos. Tal a situação existente no govêrno federal, quando a Comissão Presidencial de Administração empreendeu, como parte integrante de atividade maior, o estudơ das questões de administração de pessoal. A monografia que resultou dêsse trabalho, publicada em 1937 sob o título Personnel Administration in the Federal Service, estatuiu certos princípios básicos com respeito à divisão adequada de funções de pessoal a saber:

"A autoridade para agir em questões de administração de pessoal deverá ser delegado às repartições executivas, em grau comensurável às responsabilidades de que forem investidas para a execução dos seus respectivos programas;

As principais funções de um órgão central de pessoal, como a Comissão Federal do Serviço Civil (e, poder-se-ia acrescentar, as repartições estaduais similares) devem ser: elaborar diretrizes e normas gerais, assistir as repartições executivas em sua aplicação, impor um sistema de contrôle ùnicamente quando a revisão centra! e a rígida manutenção de padrões forem mais importantes do que a rapidez a eccnomia e a eficiência das repartições executivas, na obtenção dos resultados dos programas;

As funções de pessoal de uma repartição executiva devem ser: determinar os meios de tornar eficientes as diretrizes e padrões gerais, bem como aplicar, em definitivo, essas diretrizes a êsses padrões a casos específicos".

Por outras palavras, a primeira condição de um bom sistema de pessoal consiste na correta distribuição de responsabilidades entre o órgão central de pessoal e as repartições executivas, de par com a existência de um sistema de organização que mantenha essas responsabilidades em campos distintos, mas 
capazes de cooperar entre si. Aplica-se o princípio tanto às emprêsas privadas quanto ao govêrno. A ressponsabilidade primária em matéria de administração de pessoal recai sôbre o chefe da repartição executiva, assistido pelo seu departamento de pessoal, ao passo que a repartição central só se envolve naquilo que fôr necessário para que sejam aplicadas as diretrizes gerais, e, bem assim, facilitados os trabalhos dos programas de ação.

Em conseqüência do relatório da Comissão Browlow, baixou o Presidente uma ordem executiva, em 1938, nos têrmos da qual todos os principais departamentos (ministérios) e repartições independentes do govêrno federal ficaram obrigados a instituir - se porventura já não a possuíssem - uma divisão de pessoal, subordinada a um diretor. As atividades de todos os diretores de pessoal do govêrno federal e as da Comissão do Serviço Civil deveriam, ainda, ser planejadas e coordenadas por um Conselho de Administração de Pessual. Anteriormente, os diretores de pessoal dos ministérios eram considerados agentes da Comissão de Serviço Civil e a esta se dirigiam para o fim de receber instruções. Hoje são êles, de fato servidores dos ministérios e, apenas incidentalmente, agentes da Comissão nas questões sôbre as quais esta possuir jurisdição.

Definidas e divididas as responsabilidades e estabelecidos os critérios de organização, e subseqüente condição principal de um moderno sistema de pessoal consiste em adotar medidas positivas a fim de recrutar, estimular e conservar o melhor potencial humano disponível. Quando C. A. Dykstra foi administrador da cidade de Cincinati, pediram-lhe, certa vez. que citasse a lição mais importante que recebera durante os seus cinco anos no pôsto. Respondeu que não havia sido o esfôrço dispendido em manter os empistolados fora do serviço público, mas, sim, o que fizera a cidade no sentido de inspitar os servidores no seu trabalho. Necessita o govêrno de um programa positivo de recrutamento concebido de molde a obter-se o concurso das capacidades existentes, e dotado de critérios de nomeação suficientemente flexíveis para que se consiga a pessoa mais capaz para cada pôsto, bem como de um programa de ensino destinado aos servidores já admitidos, um sistema de remuneração baseado no rendimento do trabalho um regime adequado de férias e licenças por motivơ de doença, e um sistema de aposentadorias, de par com a manutenção de relações cordiais entre a administração e os servidores, E. segurança de promoções nas carreiras no âmbito de cada repartição como também no campo maior que abranja várias repartições a fim de garantir-se a existência de serviços de carreira. Muitos dêsses objetivos, senão a sua maioria, só poderão ser atingidos pela ação de um chefe geral compreensivc. ajudado pela existência de relações harmoniosas entre a sua divisão de pessoal e a Comissão do Serviço Civil. O trabalho por equipes e o moral dos servidores não poderão ser assegurados quando se considera a administração do pessoal como categoria distinta da ação executiva, e como um freio à mesma. O antigo papel do administrador de pessoal, no govêrno, tido como policial atento a fim de manter os afilhados políticos fora dos quadros do serviço público , é conceito antiquado. 
Dez anos depois de haver a Comissão Brownlow realizado os seus trabəlhos, confirmou a Comissão Hoover as verificações anteriores e acentuou, ainda, os seguintes pontos: a necessidade de recrutar os jovens melhor habilitados, de ambos os sexos, para os postos iniciais de natureza profissional liberal, científico. técnica e administrativa; o estabelecimento de diretrizes amplas no concernente a vencimentos e salários; a inauguração de um sistema adequado de promoções dos servidores de carreira, de um nível de responsabilidades para o imediatamente superior; a concessão de oportunidades aos servidores para que ofereçam sugestões e aperfeiçoem a eficiência dos trabalhos; a elaboração de processos fidedígnos de avaliação da eficiência; o emprêgo de métodos justos de expurgo dos servidores ineficientes e desnecessários; a aboliçãa do sistema mediante o qual a redução do número de servi. dores determina a redução dos vencimentos do seu chefe ou supervisor.

Êsses objetivos têm sido, nos últimos anos, progressivamente traduzidos esn ação administrativa. O alvo em mira é o de obter-se o máximo do potencial humano disponível, através do trabalho por equipes e da manutenção do moral elevado. A maior parte dêsses objetivos serão devidamente discutidos em capítulos ulteriores, embora sejam êles citados nesta altura, porquanto revelam as múltiplas relações de cooperação que atualmente existem entre os diretores de pessoal e os administradores gerais. No que diz respeito às repartições executivas a consecução dêsses objetivos significa, inicialmente, obter o apoio da administração superior no que concerne a criteriosas diretrizes e práticas em matéria de pessoal. Em seguida, deverão voltar-se as atenções para a questão do aprimoramento da supervisão e, bem assim, para que a classificação de cargos seja utilizada como instrumento de adminisrtação e não como um fim em si mesma. Deve ser igualmente realçada a questão do treinamento dos servidores, a da designação de cada qual para o lugar adequado, a da utilização econômica do pessoal, a do estabelecimento de um programa progressivo de relações entre os servidores e a da melhoria das condições de trabalho. No que se refere cumulativamente à administração superior e às divisões de pessoal, a nova atitude significa programa de simplificação do trabalho, adequados padrões de rendimento das atividades, exame crítico periódico dêsse rendimento, estudo do tempo de execução das atividades avaliação da eficiência, planos de auxílio, adaptação e orientação devidos aos servidores recém-admitidos, tratamento compreensivo das queixas dos servidores e o estabelecimento de um sistema de entrevistas.

Nesse quadro geral, o papel das comissões de serviço civil é consideràvelmente inferior ao do passado. Segundo o moderno modo de ver, deverão as comissões continuar a delegar às repartições executivas tantas funções quantas fôr possível e concentrar suas atividades na elaboração de diretrizes e normas de caráter geral, no auxílio, quanto à sua aplicação. A imposição de contrôles e a revisão central de métodos e processos existirão sòmente na medida em que isso seja mais importante, no interêsse público do que a conveniência dos executores dos programas administrativos. 